\title{
Inferior Turbinate
}

National Cancer Institute

\section{Source}

National Cancer Institute. Inferior Turbinate. NCI Thesaurus. Code C32794.

The largest of three pairs of conchae (superior, middle and inferior) located in the nasal cavity that is composed of spongy bony and a mucous membranes, which is highly vascular and semi-tumescent. 